\title{
Hybrid Voltage Control Model for Hybrid Renewable Energy System Using Artificial Bees Colony Algorithm
}

\author{
Mahendran Krishnamoorthy ${ }^{1^{*}}$, Prabha Umapathy ${ }^{2}$ \\ ${ }^{1}$ Department of Electrical \& Electronics Engineering, Jansons Institute of Technoloy, Karumathampatti, \\ Coimbatore \\ ${ }^{2}$ Department of Electrical \& Electronics Engineering, Sri Ramakrishna Engineering College, Vattamalaipalayam, \\ Coimbatore \\ Email: "mahae1987@gmail.com
}

Received 22 March 2016; accepted 15 April 2016; published 29 July 2016

Copyright (C) 2016 by authors and Scientific Research Publishing Inc.

This work is licensed under the Creative Commons Attribution International License (CC BY).

http://creativecommons.org/licenses/by/4.0/

(c) (i) Open Access

\begin{abstract}
This paper proposed a hybrid control model-based voltage control of Hybrid Energy System (HES) that includes both solar and wind energy conversion systems. The proposed hybrid voltage control model is the combination process of both the Artificial Bees Colony algorithm (ABC) and Proportional Integral controller (PI). The novelty of the proposed method is intelligent foraging behavior of honey bee swarm, which provides random reduction and ability to adapt complex optimization problems. Here, the $\mathrm{ABC}$ optimizes the gain parameters under various operating conditions using the minimized Square Error (SE). It considers the actual voltage outcome of the buck converter and the set point voltage. By using the optimized gain parameters, the PI controller is operated. Each separate energy conversion system is controlled by the separate proposed hybrid voltage control model. The proposed method is implemented in MATLAB/Simulink platform and the performance is verified using the comparative analysis with the existing techniques. The comparison results prove the superiority of the proposed method.
\end{abstract}

\section{Keywords}

HES, ABC, PI, SE, Voltage

\section{Introduction}

Rapid depletion of non-renewable resources worldwide and release of greenhouse gases to the atmosphere have

${ }^{*}$ Corresponding author.

How to cite this paper: Krishnamoorthy, M. and Umapathy, P. (2016) Hybrid Voltage Control Model for Hybrid Renewable Energy System Using Artificial Bees Colony Algorithm. Circuits and Systems, 7, 2795-2806.

http://dx.doi.org/10.4236/cs.2016.79238 
contributed to global warming which has necessitated an urgent search for alternative energy sources to cater to the present day's demand [1]-[3]. More importantly, these non-renewable energy resources are quickly dwindling and will no longer be available in the near future due to rapid exploitation [4]. Alternative energy technologies, like wind- and solar-based energy generation systems, are receiving national and worldwide attention owing to the rising rate of consumption of nuclear and fossil fuels [5]. Renewable energy has the potential for infinite use by end users with improved control devices and techniques [6]. With their advantages of being abundant in nature and nearly nonpolluting, renewable energy sources have attracted wide attention [7] [8]. These renewable energies are motivated by a will to reduce green-house gases (GHG) emissions and the increase of fuel prices that drives up the prices of energy [9]. There are several ways by which electricity can be generated locally using renewable sources such as solar, wind, biogas, etc. [10].

Hybrid Renewable Energy Systems (HRES), combine two or more complementary renewable sources like wind and solar and one or more conventional sources like diesel generator [11], and equipment for the storage of energy [12]. Hybrid Renewable Energy Systems are usually more reliable and less costly than other type of renewable systems that rely on a single source of energy [13]-[15]. HRES is becoming popular for stand-alone power generation in isolated sites due to the advances in renewable energy technologies and power electronic converters which are used to convert the unregulated power generated from renewable sources into useful power at the load end [16]. One of the most promising applications of renewable energy technology is the installation of hybrid energy systems in remote areas, where the grid extension is costly and the cost of fuel increases drastically with the remoteness of the location [17].

A hybrid system can supply power AC or DC or both. Component or system control or both is used to regulate the overall system operation [18]. The appropriate selection of the hybrid system's components, its optimal sizing and operation control are essential and challenging steps in hybrid energy systems and minimizing the equivalent pollutant emissions of the hybrid system is one more objective [19]. There are many optimization algorithms applied to calculate the capacity allocation for the renewable energy based hybrid power system. In addition, more control models are used to control the frequency deviation and optimal operation [20].

This paper proposed a hybrid control model-based voltage control of Hybrid Energy System (HES) that includes both solar and wind energy conversion systems [21]-[23]. The proposed hybrid voltage control model is the combination process of both the Artificial Bees Colony algorithm (ABC) and Proportional Integral controller (PI). The novelty of the proposed method is intelligent foraging behavior of honey bee swarm, which provides random reduction and ability to adapt complex optimization problems. Here, the ABC optimizes the gain parameters under various operating conditions using the minimized Square Error (SE). It considers the actual voltage outcome of the buck converter and the set point voltage. By using the optimized gain parameters, the PI controller is operated. Each separate energy conversion system is controlled by the separate proposed hybrid voltage control model [24]-[32].

\section{HES with Proposed Voltage Control Model}

The HES consists of three main parts such as wind energy conversion system, solar energy conversion system and full bridge inverter. The structure of the HES with proposed voltage control model is described in Figure 1. The wind energy conversion system is comprised of permanent magnet synchronous generator, uncontrolled full bridge rectifier and buck converter proposed hybrid voltage control model. The solar energy conversion system contains solar panels and buck converter with proposed hybrid voltage controller. Both the systems are connected to the three phase full bridge inverter using the inter phase transformer. The control pulses of the full bridge inverter are attained from the Sinusoidal Pulse Width Modulation (SPWM) scheme. The outcome of the inverter is three phase sinusoidal AC voltage, which is allowed to serve the load via three phase step up transformer.

The wind turbine converts wind speed into mechanical energy using wind turbines shaft of the generator. The buck converter of the wind energy conversion system is controlled by the proposed hybrid voltage controller. It tracks the reference voltage and adjusts the output voltage to the reference voltage.

PV cells, which are electrical devices, convert light energy to electrical energy. The energy that is obtained from solar PV panels is sustainable. This semiconductor panel absorbs photons from sunlight and releases electrons from atoms and so a potential difference is generated. This makes a current flow in the material to neglect the potential difference and hence the electricity is captured. 


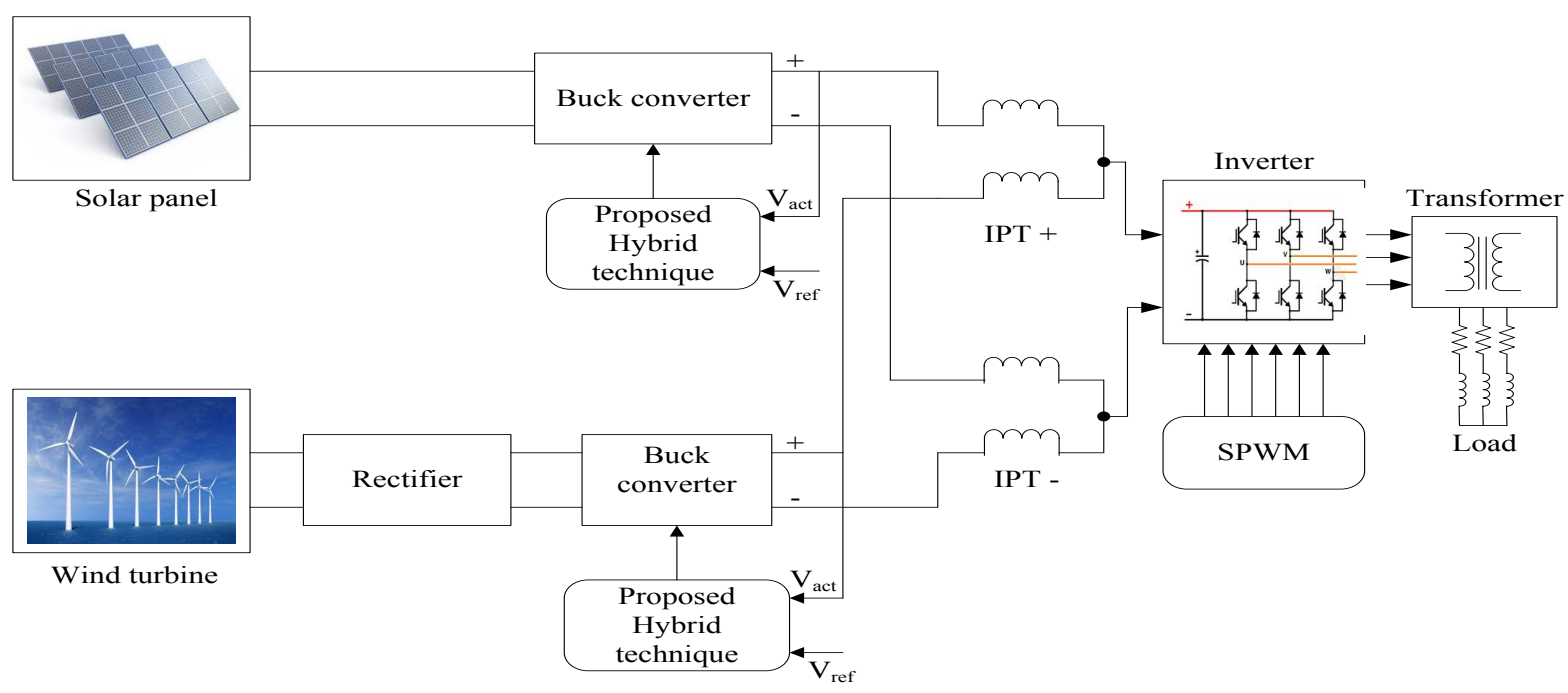

Figure 1. Structure of the HES with proposed control model.

The outcomes of both the systems are connected to the inter phase transformer, which is used to absorb voltage difference between DC voltages of two converters at any instant and ensures independent operation without any circulating current [33]. The three phase full bridge inverter is used to give the three phase AC sinusoidal voltage to the load via three phase transformer. The three phase full bridge inverter is designed by six controlled switches, which have been controlled by the SPWM scheme.

\section{Proposed hybrid voltage control model}

This section describes the proposed hybrid voltage control model, which is the combination of both the ABC algorithm and PI controller. The ABC algorithm works based on the foraging performance of honey bees for solving numerical optimization problems [34] [35]. It is one of the swarm intelligence optimization algorithms. Generally, ABC consists of three phases such as employed bee phase, onlooker bee phase and scout bee phase. Their efficient determination of food sources improves the reliability of ABC. Here, the ABC algorithm optimizes the proportional gain $k_{P}$ and Integral gain $k_{I}$ parameters of the PI controller by using the objective function, i.e., minimization of Square Error (SE). The actual output voltage of the buck converter and the set point voltage are considered as the input parameters of the ABC. From the optimized parameters, the PI controller has been operated. In contrast, gain constants are determined only once in conventional controllers and so they can be operated only at restricted operating point changes. This makes these controllers unsupportive where robust performance is required. Initially, the gain parameters are randomly generated with the required limit, which is described in the following Equation (1).

$$
X_{i}=X_{i}^{\min } \leq X_{i} \leq X_{i}^{\min }, \forall i=1,2 \ldots n
$$

where, $X_{i}=\left[k_{P}^{i}, k_{I}^{i}\right]$ are the gain parameters; the employed bee attains elite fitness function from Equation (2) and the onlooker bee improve the velocity of the input populations using Equation (3).

$$
\begin{gathered}
F(E)=\left\{\frac{1}{2}\left(\Delta V_{i}\right)^{2}\right\} \\
V_{i, j}=X_{i, j}+F(E)_{i, j}\left(X_{i, j}-X_{k, j}\right)
\end{gathered}
$$

where, $\left(\Delta V_{i}\right)^{2}=\left(V_{i}^{\text {ref }}-V_{i}^{\text {act }}\right)^{2}, \forall i=1,2 \ldots n$ is the SE; $k=(1,2,3 \ldots n)$ and $j=(1,2,3 \ldots n)$ are the randomly chosen indices. From the onlooker bee, the probability formula for selecting the nectar source can be expressed as follows,

$$
\text { probability }=\frac{F(E)}{\sum_{i=1}^{n} F(E)}
$$


If better solutions are not achieved, abandon the solutions and produce the random number of scout bee solutions using the following Equation (5).

$$
x_{i}^{j}=x_{\min }^{j}+\operatorname{rand}[0,1]\left(x_{\max }^{j}-x_{\min }^{j}\right)
$$

Then, the fine fitness of new food sources are determined using Equation (2) and the best solution refers to optimal gain parameters. The steps to find the optimal gain parameters to tuning the PI controller using ABC algorithm are explained below.

Steps of the ABC algorithm:

Step 1: In the first step, initialization of all the parameters of the algorithm, such as input parameters' limits and random population $\mathrm{N}$ limits are done. Here, the actual output voltage of the buck converter and the set point voltage are applied as the input.

Step 2: Randomly generate the gain parameters $k_{P}$ and $k_{I}$ according to the specified limit, which is attained in the employed bee phase.

Step 3: The random solutions are applied in the fitness Equation (2) and find the best solution.

Step 4: The neighborhood search of the onlooker bee phase varies to velocity of the input population using Equation (3) to determine solutions.

Step 5: Categorize the obtained solutions as best solution set and worst solution set.

Step 6: Determine the neighborhood search space size for every best solution set and generate solutions from the selected neighborhood search space.

Step 7: When there could not be best solution set from onlooker bee phase, discard the solutions and fill it with random scout bee solutions, which can be generated using Equation (4).

Step 8: Find the best solution from each set and determine the associated fuel cost to meet load demand.

Step 9: Check the stopping criterion. If satisfied, terminate the search, else go to step 10.

Step 10: Assign the new population to generate new solutions. Go to Step 2.

Once the process is finished, the $\mathrm{ABC}$ is ready to give the optimum tuning parameters for the PI controller. The output of the $\mathrm{ABC}$ is varied according to the variation in outcome of the buck converter (Figure 2).

\section{Results and Discussion}

The proposed method is implemented in MATLAB. Here, the PMSG wind turbine and PV system are utilized for testing the proposed hybrid voltage control technique. The effectiveness of the proposed model effectiveness is analyzed by comparing with that of the conventional technique. The implemented model of HES is described in the following Figure 3.

The line voltage measured at the output of the inverter is shown in Figure 4. Figure 5 is segregated into three sections and labeled as (a), (b) and (c) for output voltage, output current and output power of the wind turbine. The WECS rectifier output DC voltage, current and power using proposed method are explained in Figure 6. The attained total DC voltage is applied to the full bridge inverter via interphase transformer.

The solar plant DC outcomes using proposed hybrid voltage control technique are measured in the 0.04 second simulation time, which are depicted in Figure 7. Here, the DC output voltage and current of the solar plant are illustrated in Figure 8(a) and Figure 8(b) respectively. The output dc power is explained in Figure $8(c)$. The performance of the proposed method is compared with that of the normal PI controller, which is described in the following section.

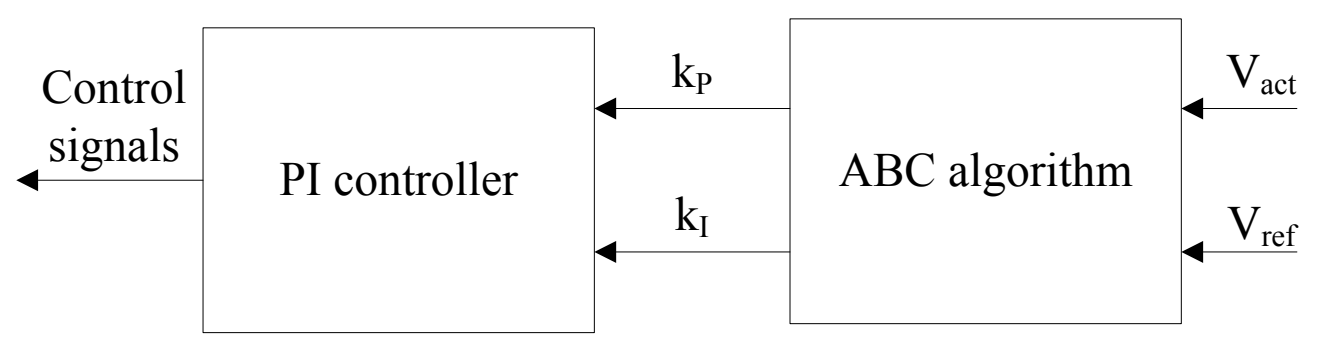

Figure 2. PI controller with $\mathrm{ABC}$ algorithm. 


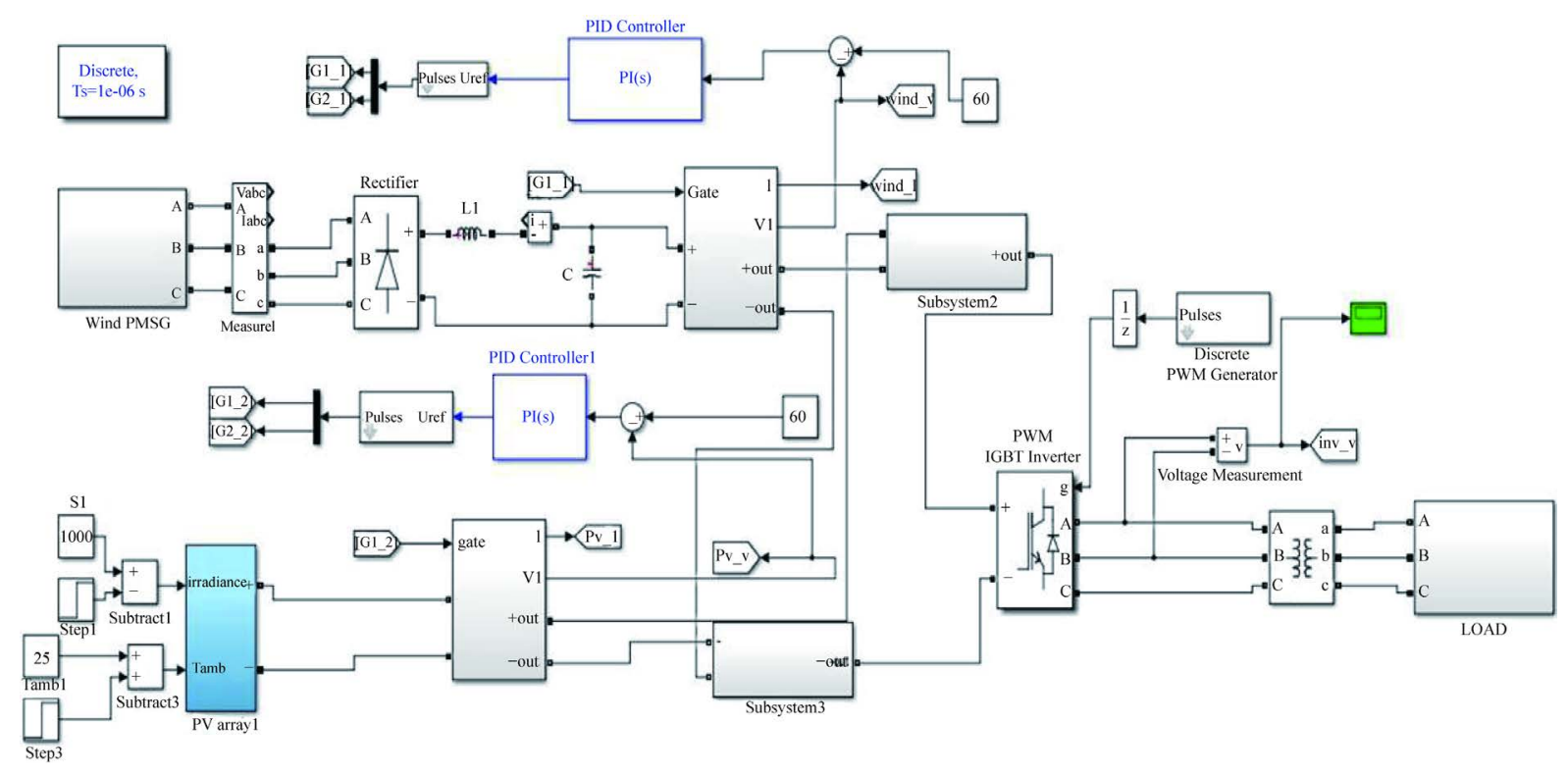

Figure 3. HES with controller model.

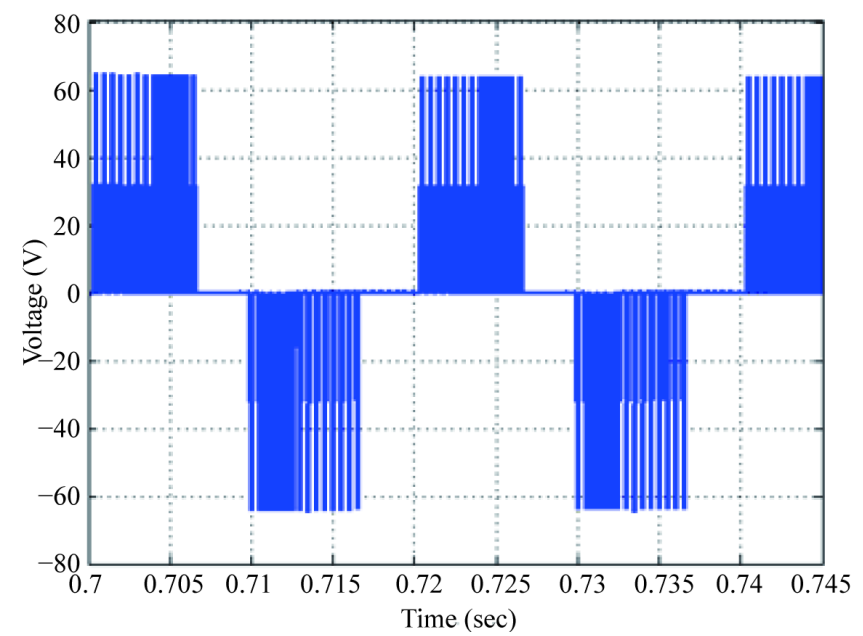

Figure 4. Inverter AC output voltage using proposed technique.

The DC line voltages of the inverter performance using proposed hybrid technique and normal PI controller are compared in Figure 9. The upper curve illustrates the inverter voltage using the proposed technique and the lower curve shows the inverter voltage using the PI controller. Here, the AC voltage lies between the $-60 \mathrm{~V}, 0$ and $60 \mathrm{~V}$ but the PI controller technique has unstable voltage levels at the end of the operating condition compared to the proposed technique. The phase voltage of the inverter comparison is depicted in Figure 10, which is tested under 0.945 second simulation time. The upper curve represents the inverter phase voltage using the proposed hybrid voltage control technique, which has the line voltage $230 \mathrm{~V}$ and $120^{\circ}$ phase shift for each phase. The lower curve signifies the inverter phase voltage using the PI controller, which has also the amplitude same as that of the proposed method but the phase shift differs from the proposed technique and shows high distortion.

The waveforms obtained from the wind turbine using the proposed technique and the PI controller technique are explained in Figure 10, which is segregated in to three segments and labeled as (a), (b) and (c) for output voltage, output current and output power respectively. Figure 10(a) illustrates wind turbine output voltage comparison. Here, the wind turbine voltage has the minimum distortion and settling time compared to those of the PI controller. 


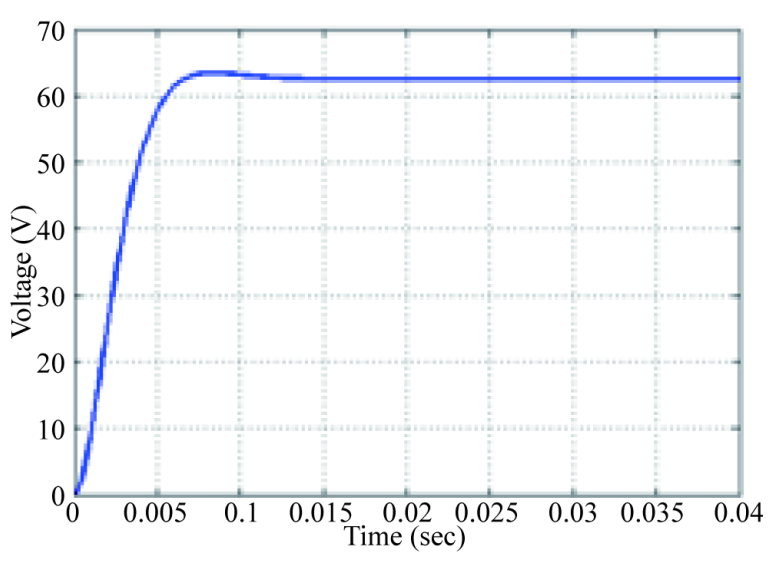

(a)

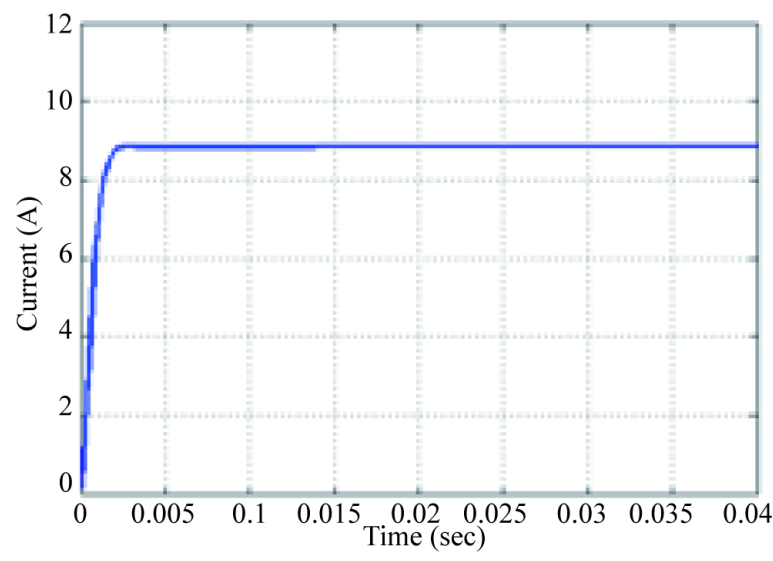

(b)

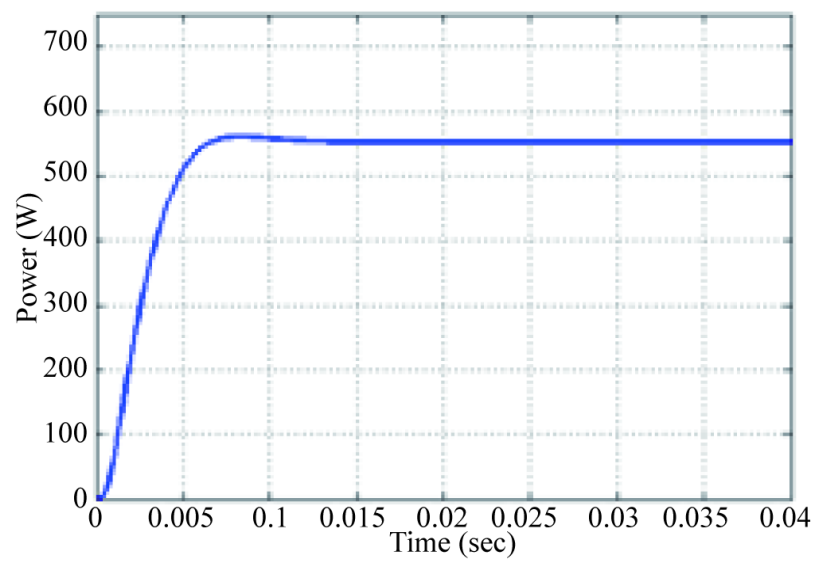

(c)

Figure 5. Waveform analysis of wind turbine using proposed technique (a) Output voltage (b) Output current and (c) Output power.

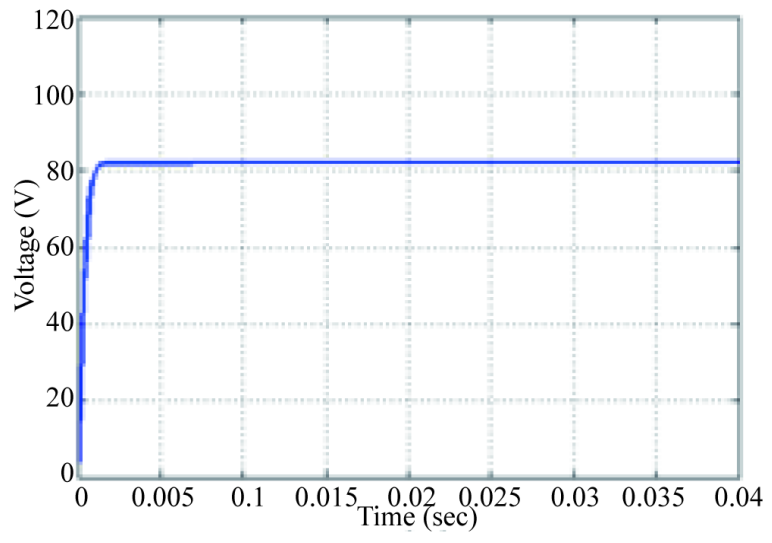

(a)

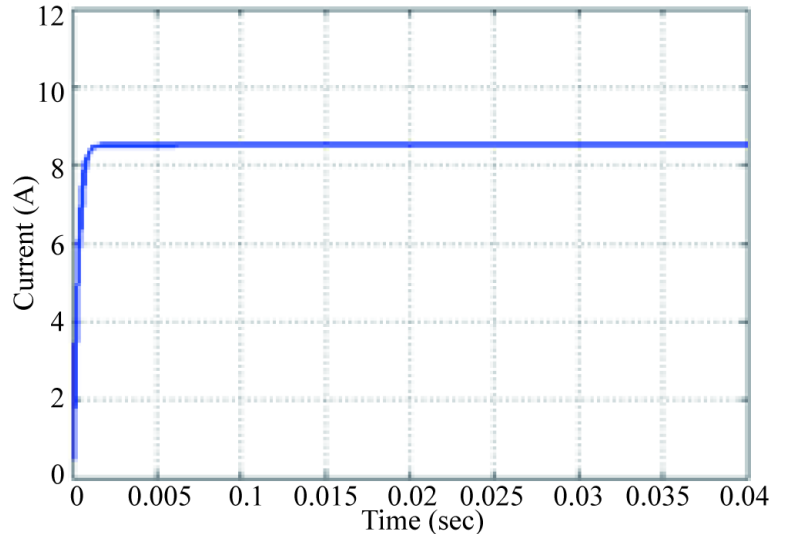

(b)

Figure 6. Waveform of WECS rectifier using proposed technique (a) Output voltage and (b) Output current.

The WECS rectifier performances using different techniques like the proposed hybrid voltage control method and the PI controller technique are explained in Figure 11, which is classified into two labels such as Figure 11(a) for output voltage comparison and Figure 12(b) for output current comparison. It is seen that the PI controller has high rise time, peak overshoot and settling time compared to those of the proposed technique. The 

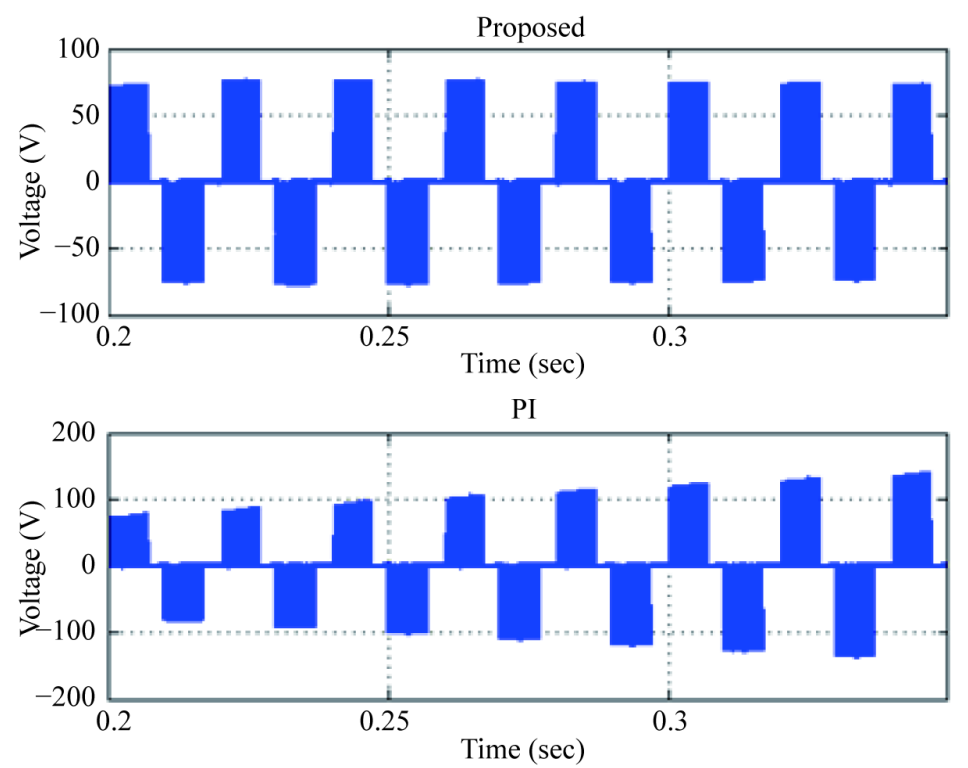

Figure 7. Inverter output voltage comparison.

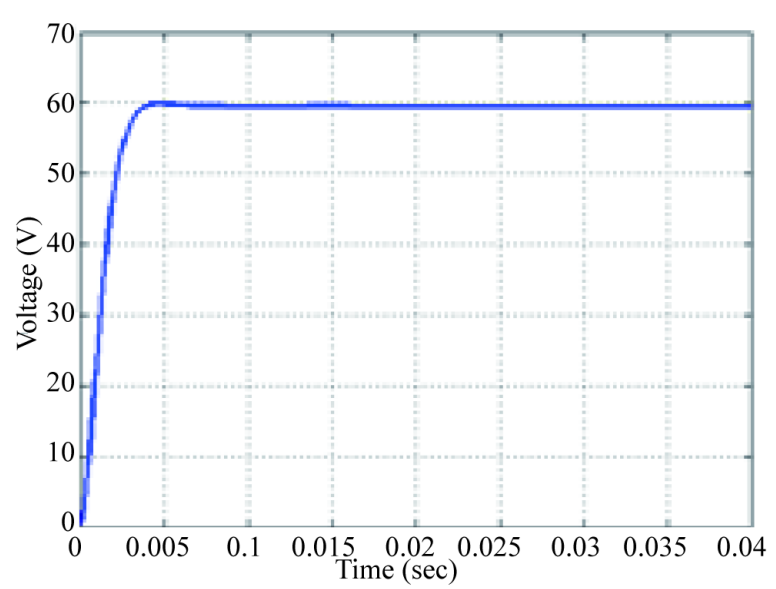

(a)

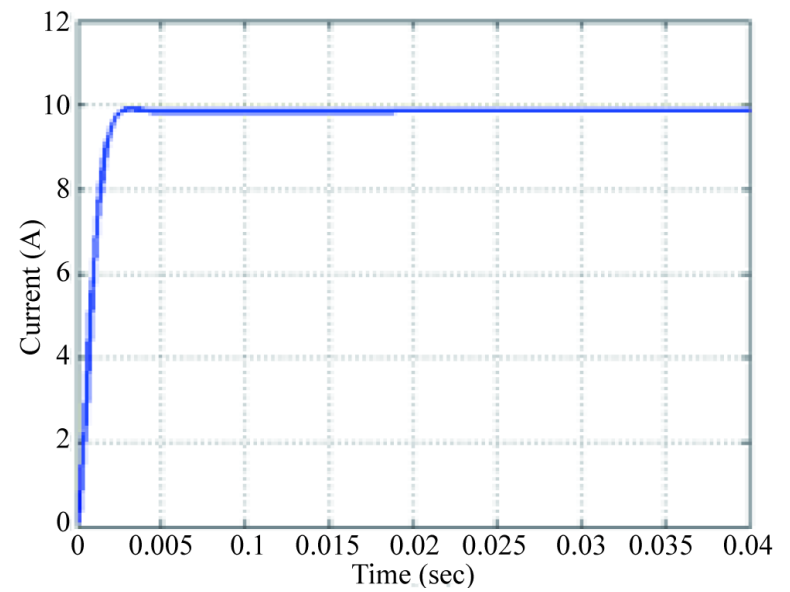

(b)

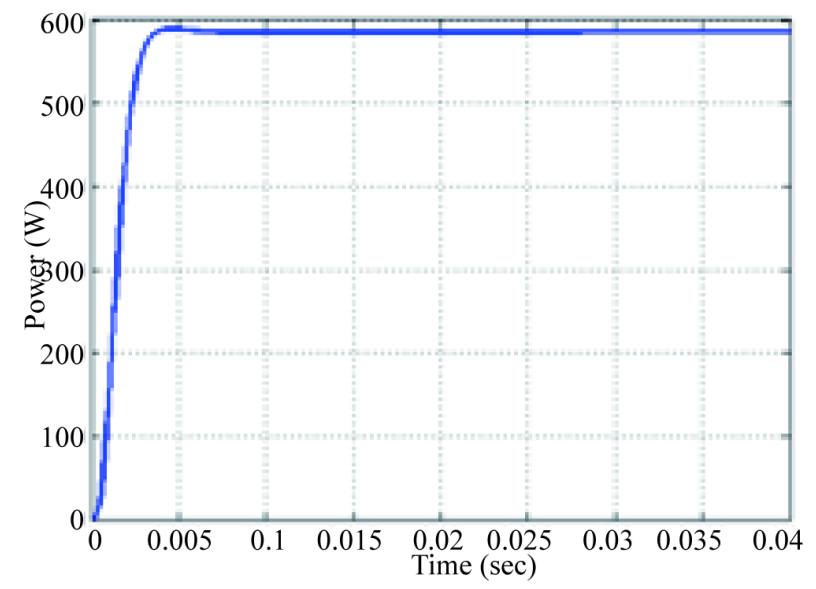

(c)

Figure 8. Waveform analysis of solar plant using proposed technique (a) Output voltage (b) Output current and (c) Output power. 

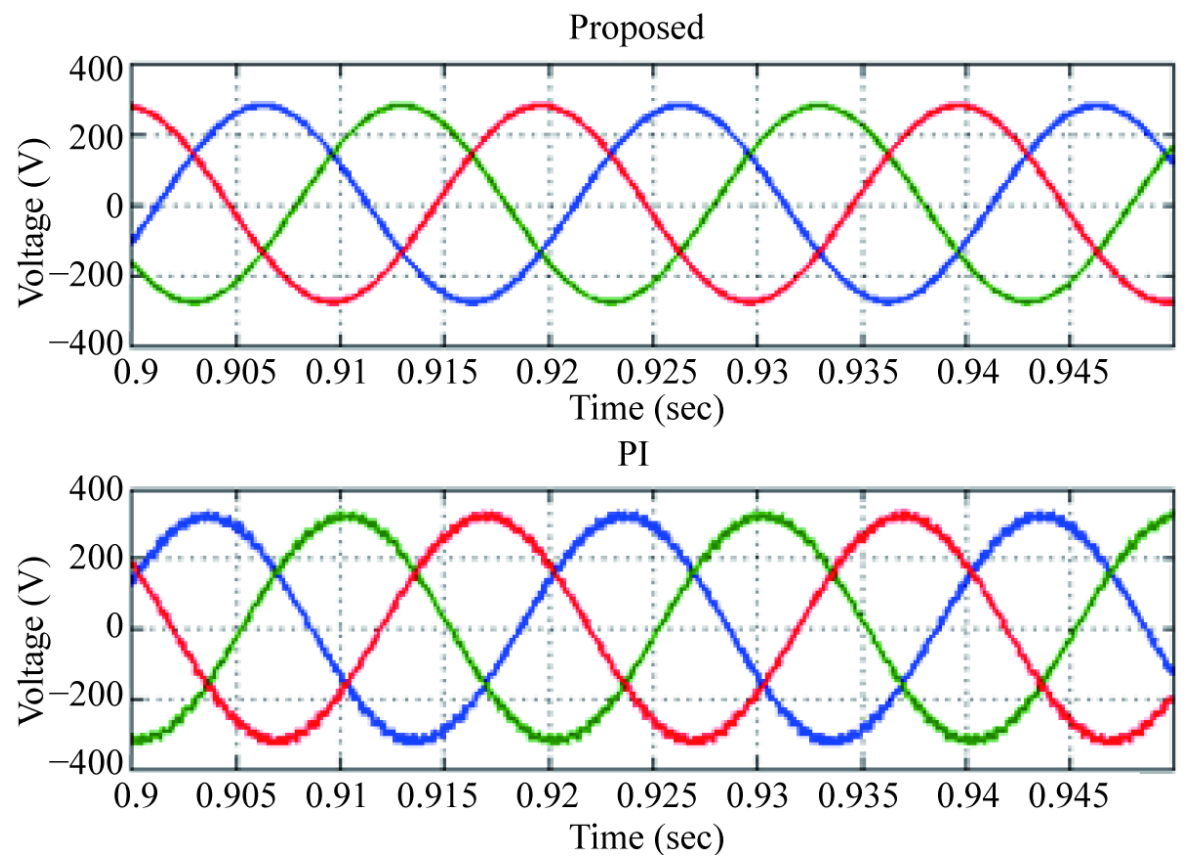

Figure 9. Inverter phase voltage comparison.

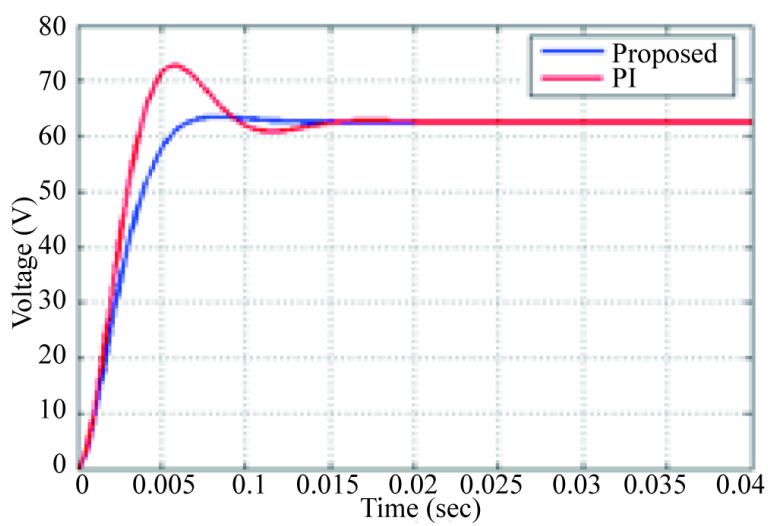

(a)

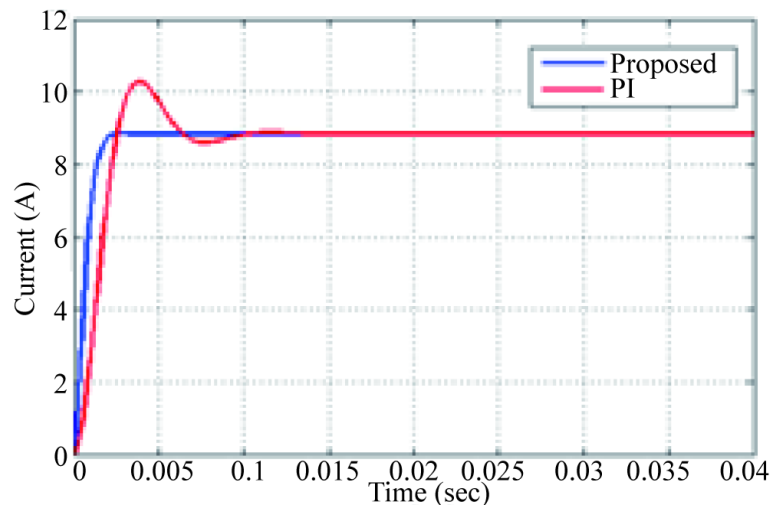

(b)

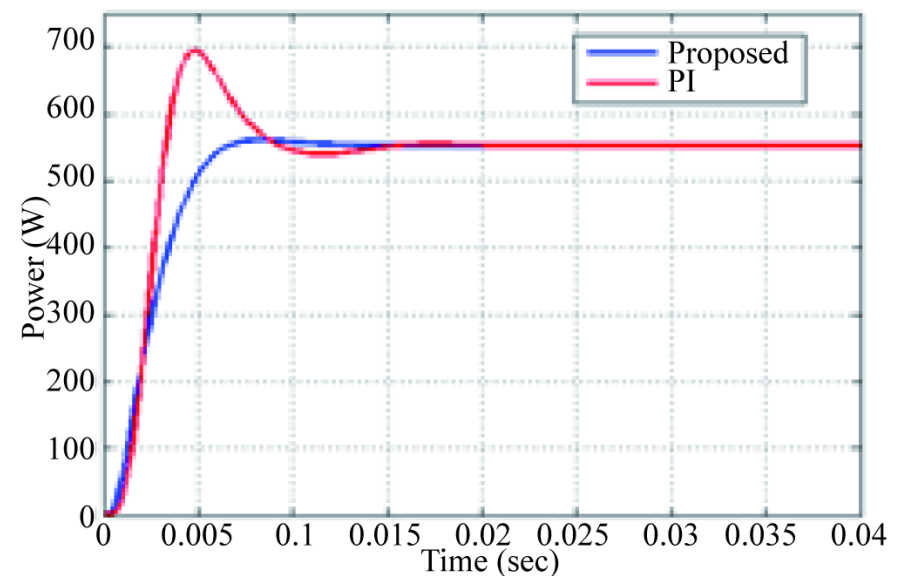

(c)

Figure 10. Waveform comparison of wind turbine (a) Output voltage (b) Output current and (c) Output power. 


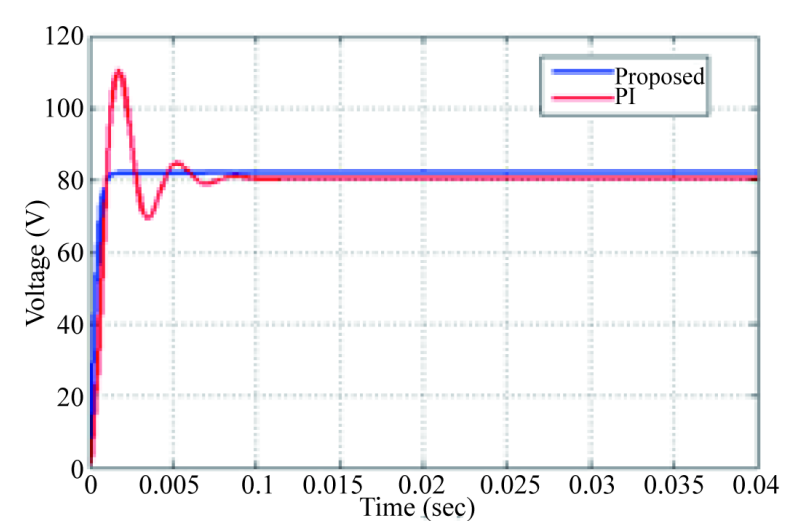

(a)

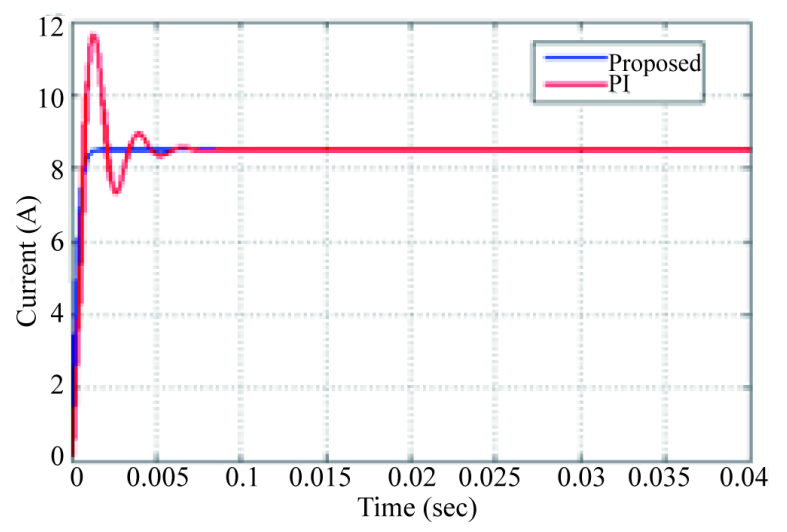

(b)

Figure 11. Waveform comparison of WECS rectifier, (a) Output voltage and (b) Output current.

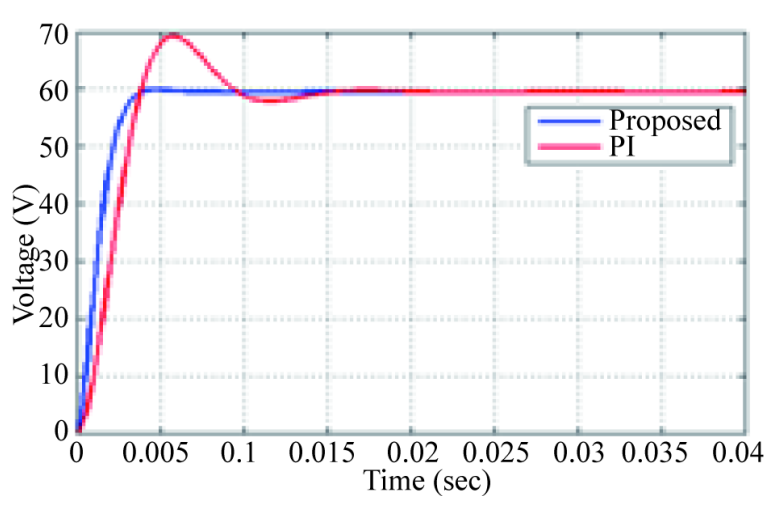

(a)

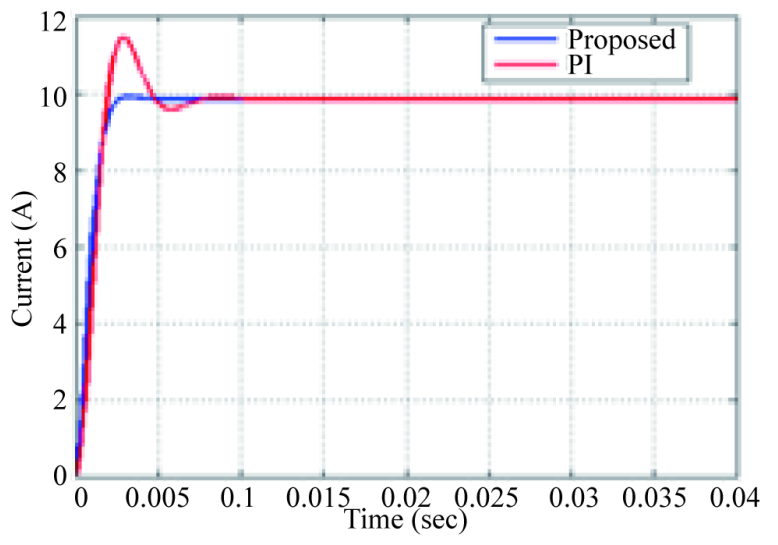

(b)

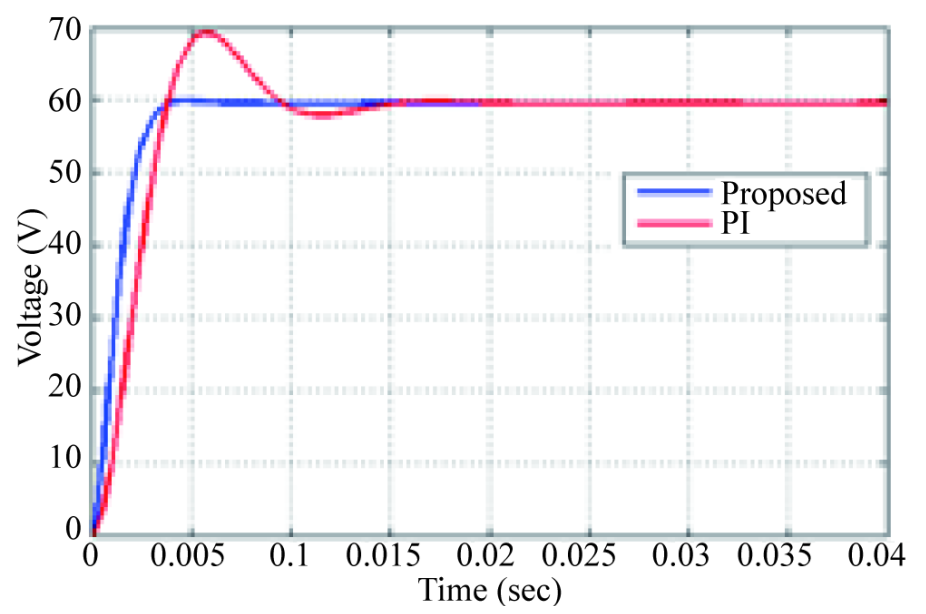

(c)

Figure 12. Waveform comparison of solar plant (a) Output voltage (b) Output current and (c) Output power.

waveform comparison of solar plant is explained in Figure 13. Figure 12(a) describes the DC output voltage of the solar plant. Here, the solar plant output voltage using the PI controller has 0.004 second rise time and settled at the 0.02 second. The proposed voltage control technique has 0.003 second rise time with 0.005 second settling time. Figure 12(b) explains the solar plant output DC current comparison and Figure 12(c) describes the solar plant output power comparison. It clearly shows that the PI controller technique does not exactly 

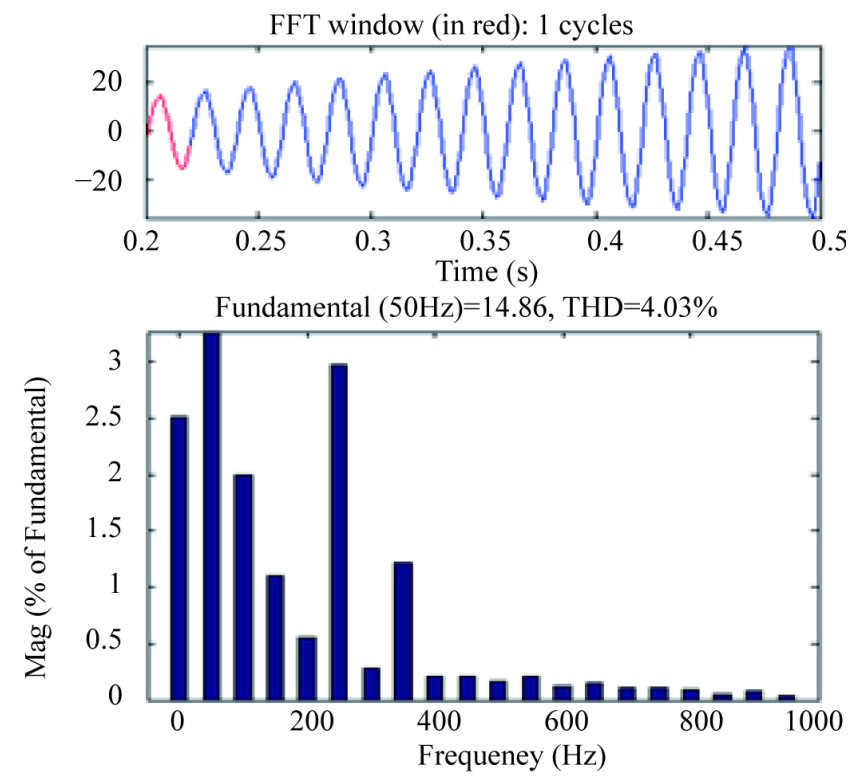

Figure 13. Voltage THD of the inverter using PI controller.
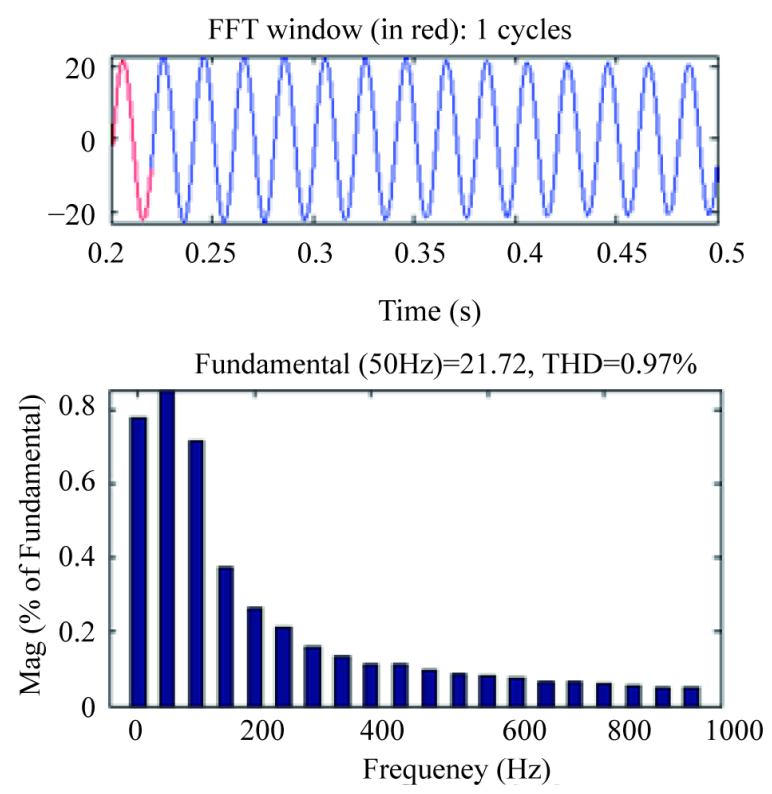

Figure 14. Voltage THD of the inverter using proposed controller.

control the distortions present in the solar plant outcome compared to the proposed technique. On the other hand, the proposed voltage control technique effectively maintains the stability of the system. Then the inverter output AC voltage THD spectrum is analyzed in the above Figure 14. In Figure 14, the inverter voltage THD spectrum using the PI controller is explained, which consists of $4.09 \%$ of THD that explains the inverter output voltage spectrum using the proposed voltage control technique. It is seen that the proposed method has $0.97 \%$ of THD. From the comparison analysis, we can finalize that the proposed method effectively maintains the system stability with low harmonics.

\section{Conclusion}

In the paper, proposed study introduced hybrid control model-based voltage control of HES. Both the most pop- 
ular renewable sources of energy, solar energy source and wind energy source, were individually modeled and then combined to represent a distributed generation system in the Simulink model. The DC buck converters for HES have been designed to supply the generated voltage with stability to the load under various operating conditions using the proposed control model. In the proposed control model, PI controller had worked based on the optimized gain parameters obtained from the $\mathrm{ABC}$ algorithm. The effectiveness of the proposed method had been evaluated by comparative analysis with different conventional control techniques. The modeled distributed generation system had been verified by generated phase voltages for its conversion efficiency with total harmonic ration of voltage (THD) at $0.97 \%$. The effectiveness of the proposed method had been proved by the obtained simulation results and comparative analysis.

\section{References}

[1] Zhou, W., Lou, C.Z., Li, Z.S., Lu, L. and Yang, H.X. (2010) Current Status of Research on Optimum Sizing of Stand-Alone Hybrid Solar-Wind Power Generation Systems. Applied Energy, 87, 380-389. http://dx.doi.org/10.1016/j.apenergy.2009.08.012

[2] Razak, N.A.A., Othman, M.M. and Musirin, I. (2010) Optimal Sizing and Operational Strategy of Hybrid Renewable Energy System Using HOMER. Proceedings of Power Engineering and Optimization, June, 495-501.

[3] Tina, G.M. and Gagliano, S. (2011) Probabilistic Modeling of Hybrid Solar/Wind Power System with Solar Tracking System. Renewable Energy, 36, 1719-1727. http://dx.doi.org/10.1016/j.renene.2010.12.001

[4] Bhattacharya, P., Mukhopadhyay, S., Ghsoh, B.B. and Bose, P.K. (2012) Optimized Use of Solar Tracking System and Wind Energy. Procedia Technology, 4, 834-839. http://dx.doi.org/10.1016/i.protcy.2012.05.137

[5] Qi, W., Liu, J.F., Chen, X.Z. and Christofides, P.D. (2011) Supervisory Predictive Control of Standalone Wind/Solar Energy Generation Systems. IEEE Transactions on Control Systems Technology, 19, 199-207. http://dx.doi.org/10.1109/TCST.2010.2041930

[6] Karabiber, A., Keles, C., Kaygusuz, A. and Baykant Alagoz, B. (2013) An Approach for the Integration of Renewable Distributed Generation in Hybrid DC/AC Micro Grids. Renewable Energy, 52, 251-259. http://dx.doi.org/10.1016/j.renene.2012.10.041

[7] Liu, C.H., Chau, K.T. and Zhang, X.D. (2010) An Efficient Wind-Photovoltaic Hybrid Generation System Using Doubly Excited Permanent-Magnet Brushless Machine. IEEE Transactions on Industrial Electronics, 57, 831-839. http://dx.doi.org/10.1109/TIE.2009.2022511

[8] Zeng, J., Li, M., Liu, J.F., Wu, J. and Ngan, H.W. (2010) Operational Optimization of a Stand-Alone Hybrid Renewable Energy Generation System Based on an Improved Genetic Algorithm. Proceedings of Power and Energy Society, July, 1-6.

[9] Vadirajacharya and Katti, P.K. (2012) Rural Electrification through Solar and Wind Hybrid System: A Self Sustained Grid Free Electric Power Source. Energy Procedia, 14, 2081-2087. http://dx.doi.org/10.1016/j.egypro.2011.12.1211

[10] Notton, G., Diaf, S. and Stoyanov, L. (2011) Hybrid Photovoltaic/Wind Energy Systems for Remote Locations. Energy Procedia, 6, 666-677. http://dx.doi.org/10.1016/j.egypro.2011.05.076

[11] Belmili, H., Haddadi, M., Bacha, S., Almi, M.F. and Bendib, B. (2014) Sizing Stand-Alone Photovoltaic-Wind Hybrid System: Techno-Economic Analysis and Optimization. Renewable and Sustainable Energy Reviews, 30, 821-832. http://dx.doi.org/10.1016/j.rser.2013.11.011

[12] Bakic, V., Pezo, M., Stevanovic, Z., Zivkovic, M. and Grubor, B. (2012) Dynamical Simulation of PV/Wind Hybrid Energy Conversion System. Energy, 45, 324-328. http://dx.doi.org/10.1016/j.energy.2011.11.063

[13] Fadaee, M. and Radzi, M.A.M. (2012) Multi-Objective Optimization of a Stand-Alone Hybrid Renewable Energy System by Using Evolutionary Algorithms: A Review. Renewable and Sustainable Energy Reviews, 16, 3364-3369. http://dx.doi.org/10.1016/j.rser.2012.02.071

[14] Ahmed, S., Othman, H. and Anis, S. (2010) Optimal Sizing of a Hybrid System of Renewable Energy for a Reliable Load Supply without Interruption. European Journal of Scientific Research, 45, 620-629.

[15] Bernal-Agustín, J.L. and Dufo-López, R. (2009) Simulation and Optimization of Stand-Alone Hybrid Renewable Energy Systems. Renewable and Sustainable Energy Reviews, 13, 2111-2118. http://dx.doi.org/10.1016/j.rser.2009.01.010

[16] Bajpai, P. and Dash, V. (2012) Hybrid Renewable Energy Systems for Power Generation Instand-Alone Applications: A Review. Renewable and Sustainable Energy Reviews, 16, 2926-2939. http://dx.doi.org/10.1016/j.rser.2012.02.009

[17] Das, D.C., Roy, A.K. and Sinha, N. (2012) GA Based Frequency Controller for Solar Thermal-Diesel-Wind Hybrid Energy Generation/Energy Storage System. International Journal of Electrical Power \& Energy Systems, 43, $262-279$. 
http://dx.doi.org/10.1016/j.ijepes.2012.05.025

[18] Kusakana, K. and Vermaak, H.J. (2014) Hybrid Diesel Generator/Renewable Energy System Performance Modeling. Renewable Energy, 67, 97-102. http://dx.doi.org/10.1016/j.renene.2013.11.025

[19] Wang, J. and Yang, F. (2013) Optimal Capacity Allocation of Standalone Wind/Solar/Battery Hybrid Power System Based on Improved Particle Swarm Optimization Algorithm. IET Renewable Power Generation, 7, 443-448. http://dx.doi.org/10.1049/iet-rpg.2012.0329

[20] Nema, P., Nema, R.K. and Rangnekar, S. (2009) A Current and Future State of Art Development of Hybrid Energy System Using Wind and PV-Solar: A Review. Renewable and Sustainable Energy Reviews, 13, 2096-2103. http://dx.doi.org/10.1016/i.rser.2008.10.006

[21] Das, D.C., Roy, A.K. and Sinha, N. (2012) GA Based Frequency Controller for Solar Thermal-Diesel-Wind Hybrid Energy Generation/Energy Storage System. International Journal of Electrical Power \& Energy Systems, 43, $262-279$. http://dx.doi.org/10.1016/j.ijepes.2012.05.025

[22] Malla, S.G. and Bhende, C.N. (2014) Voltage Control of Stand-Alone Wind and Solar Energy System. Electrical Power and Energy Systems, 56, 361-373. http://dx.doi.org/10.1016/j.ijepes.2013.11.030

[23] Paiva, J.E. and Carvalho, A.S. (2013) Controllable Hybrid Power System Based on Renewable Energy Sources for Modern Electrical Grids. Renewable Energy, 53, 271-279. http://dx.doi.org/10.1016/j.renene.2012.11.023

[24] Hamada, Y., Takeda, K., Goto, R. and Kubota, H. (2011) Hybrid Utilization of Renewable Energy and Fuel Cells for Residential Energy Systems. Energy and Buildings, 43, 3680-3684. http://dx.doi.org/10.1016/j.enbuild.2011.09.042

[25] Xu, L., Ruan, X., Mao, C., Zhang, B. and Luo, Y. (2013) An Improved Optimal Sizing Method for Wind-Solar-Battery Hybrid Power System. IEEE Transactions on Sustainable Energy, 4, 774-785. http://dx.doi.org/10.1109/TSTE.2012.2228509

[26] Bayod-Rujula, A.A., Haro-Larrode, M.E. and Martinez-Gracia, A. (2013) Sizing Criteria of Hybrid Photovoltaic-Wind Systems with Battery Storage and Self-Consumption Considering Interaction with the Grid. Solar Energy, 98, 582-591. http://dx.doi.org/10.1016/j.solener.2013.10.023

[27] Wu, K. and Zhou, H. (2014) A Multi-Agent-Based Energy-Coordination Control System for Grid-Connected Large-Scale Wind-Photovoltaic Energy Storage Power-Generation Units. Solar Energy, 107, 245-259. http://dx.doi.org/10.1016/j.solener.2014.05.012

[28] Kabalci, E. (2013) Design and Analysis of a Hybrid Renewable Energy Plant with Solar and Wind Power. Energy Conversion and Management, 72, 51-59. http://dx.doi.org/10.1016/j.enconman.2012.08.027

[29] Lin, W.-M. and Hong, C.-M. (2010) Intelligent Approach to Maximum Power Point Tracking Control Strategy for Variable-Speed Wind Turbine Generation System. Energy, 35, 2440-2447. http://dx.doi.org/10.1016/j.energy.2010.02.033

[30] Chen, C.H., Hong, C.-M. and Cheng, F.-S. (2012) Intelligent Speed Sensor less Maximum Power Point Tracking Control for Wind Generation System. Electrical Power and Energy Systems, 42, 399-407. http://dx.doi.org/10.1016/j.ijepes.2012.04.019

[31] Kesraoui, M., Korichi, N. and Belkadi, A. (2011) Maximum Power Point Tracker of Wind Energy Conversion System. Renewable Energy, 36, 2655-2662. http://dx.doi.org/10.1016/j.renene.2010.04.028

[32] Chang, Y.-H. and Chang, C.-Y. (2010) A Maximum Power Point Tracking of PV System by Scaling Fuzzy Control. Proceedings of the International Multiconference of Engineers and Computer Scientists, Hong Kong, March 17-19 2010, 1212-1216.

[33] Bhide, R.S. and Kulkarni, S.V. (2006) Analysis of Parallel Operation of Converters with Interphase Transformer. Proceedings of India International Conference on Power Electronics, Chennai, 19-21 December 2006, 193-196. http://dx.doi.org/10.1109/iicpe.2006.4685366

[34] Baykasoulu, A., Ozbakir, L. and Tapkan, P. (2007) Artificial Bee Colony Algorithm and Its Application to Generalized Assignment Problem. Itech Education and Publishing, Turkey. http://dx.doi.org/10.5772/5101

[35] Karaboga, D. and Basturk, B. (2007) Artificial Bee Colony (ABC) Optimization Algorithm for Solving Constrained Optimization Problems. World Congress on Foundations of Fuzzy Logic and Soft Computing, 4529, 789-798. 


\section{Submit or recommend next manuscript to SCIRP and we will provide best service for you:}

Accepting pre-submission inquiries through Email, Facebook, LinkedIn, Twitter, etc.

A wide selection of journals (inclusive of 9 subjects, more than 200 journals)

Providing 24-hour high-quality service

User-friendly online submission system

Fair and swift peer-review system

Efficient typesetting and proofreading procedure

Display of the result of downloads and visits, as well as the number of cited articles

Maximum dissemination of your research work

Submit your manuscript at: http://papersubmission.scirp.org/ 